http://ejtr.vumk.eu

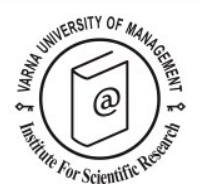

\title{
Accessible tourism in Jordan: travel constrains and motivations
}

\author{
Mamoon Allan ${ }^{1}$
}

Received: 27/06/2014 Accepted: 19/12/2014

\footnotetext{
${ }^{1}$ Faculty of Archaeology and Tourism, University of Jordan, Amman 11942 Jordan, E-mail: mamoon1073@yahoo.com
}

\begin{abstract}
The main purpose of this study was to identify the motivations and travel constrains for a sample of tourists with disabilities in Jordan. A quantitative study was conducted employing an onsite intercept questionnaire. However, the questionnaire was completed and returned by 226 members of the research cohort in Jordan. The findings of this study show that the main intrinsic motivations for the respondents to travel were escape, followed by relaxation, and enjoyment, respectively. Additionally, it found that their main extrinsic motivation was the identified regulations of extrinsic motivation and they expressed a low level of amotivation. The results of this study also indicate that travel intrinsic constrains had the prominent influence on the study cohort. The study's findings were expected to be helpful to better understanding the tourists with different types of disabilities in Jordan.
\end{abstract}

(C) 2015 Varna University of Management. All rights reserved

Keywords: Accessible tourism, disability, travel constrains, motivation, amotivation, Jordan

Citation: Allan, M. (2015) Accessible tourism in Jordan: travel constrains and motivations. European Journal of Tourism Research 10, pp. 109-119

\section{Introduction}

Tourism represents a basic human right and should be accessible to all people (Richards et al., 2010). Tourists with disabilities are regularly excluded from different types of leisure activities mainly because of different barriers and constraints (physical, social and attitudinal) (Burns et al., 2009). The international statistics approves that the rate of people with disabilities are growing worldwide and they represent about $10 \%$ of the whole world's population which equals 650 million people globally (Disabled World, 2012). Currently tourists with disabilities are considered as a growing tourism niche market and their market share is worth almost 117 billion USD per annum (Bizjak et al., 2011). According to the European Commission (2014), it is estimated that the total gross turnover of European Union's accessible tourism was $€ 786$ billion, whereas the direct gross value added of EU's accessible tourism in 2012 was about $€ 150$ billion, after taking the multiplier effect into consideration.

In the context of the Middle East, the state of people with disabilities is still commonly considered from a medical and charity approach, within a setting of a very narrow and frequently outdated legislative and policy frameworks (Axelsson \& Barrett, 2009). However, Jordan was considered as the first nation in the Middle East to act out disability- 
specific legislation and introduce building codes aimed at accessibility. The law, 'Welfare of People with Disabilities' guarantees entire incorporation into the life of the community in a wide range of fields, including education, employment and health care (MIUSA, 2013). Whilst much research has been conducted on disabilities and people with disabilities in Jordan, little empirical research into accessible tourism and its participants has found. Thus, the main purposes of this study are to identify the motivations and travel constrains for tourists with disabilities undertaking different tourism experiences in Jordan.

\section{Literature Review}

\section{Accessible tourism}

Generally speaking, there have been many myths about people with disabilities and tourism (Darcy, 1998). Communities have to increase their awareness toward the needs and requirements of people with disabilities (Yau et al., 2004). However, better understanding the different needs of individuals with disabilities is critical to providing proper information and helping them to engage in different tourism experiences (Eichhorn et al., 2008).

A disability can be defined as: "any restriction or lack (resulting from any impairment) of ability to perform an activity in the manner or within the range considered normal for a human being" (WHO, 1980). The barriers for people with disabilities can be defined as those hindrances encountered while participating or attempting to participate in any tourism experience (McGuire, 1984). However, whilst many tourists might experience barriers to tourism participation, it has been acknowledged that these barriers excessively affect people with disabilities (Smith, 1987; Kennedy et al., 1991; Foggin, 2001; Buhalis \& Darcy, 2010). Accessibility involves three levels: accessibility of the built environment, which includes lodgings, private and public spaces, structures and buildings; geographic accessibility that includes the capability to circulate; and access to information and communication which refers to accessible media, easy information distribution and data (Axelsson \& Barrett, 2009). Burnett and Baker (2001) propose that the level of support needs for people with mobility disabilities is a valuable tool for market segmentation based on environmental, access and activity criteria.

Accordingly, the literature related to the tourism experience of people with different types of disabilities was dated back to the late 1970s, 1980s and early 1990s (Poria et al., 2010). Ozturk et al., (2008) have examined the capability of the tourism industry management in Turkey to meet the requirements of disabled tourists. Thus, they assert that tourism management in Turkey is not suitably prepared to deal with disabled tourists. They specify four weakness elements: lack of qualified tourism organizations to deal with such tourists; inappropriate transportation facilities; unsuitable environmental conditions and lack of qualified people to work with disabled tourists and weakness of accessible tourism training.

Accessible tourism in Jordan

According to the Department of General Statistics (2011), the mobility (physical) disability $(17.3 \%)$ is the most prevalent type of disability in Jordan, followed by Visual disability $(16.2 \%)$, multi-disabilities (8.2\%), mental disabilities $(7.9 \%)$, and autism disorders $(0.5 \%)$.It was estimated that the number of people with disabilities was 63.00 in 2004, whereas it reached 300.000 in 2014 in Jordan (The Department of General Statistics, 2011). Following this the percentage of disabled people in Jordan reaches (4-5\%) of the population (The Department of General Statistics, 2011). However, it could be argued that the potential factors behind increasing the rate of disabled people in Jordan in the last years are due to poverty, malnutrition, and blood marriage (Peters, 2010).

It is becoming increasingly difficult to ignore the importance of disabled tourists segment in the overall tourism market in Jordan. Despite the advancement in different aspects of the tourism industry in Jordan, tourists with disabilities are still confronted many barriers and problems to travel and experience different tourism activities (Allan, 2013). Hitherto, researchers have shown an increased interest in the issue of disability in Jordan and a considerable amount of literature has conducted on different issues related to disability in Jordan (Turmusani \& Sime, 1994; Turmusani, 1999, 2003; Rutherford, 2007, Allan, 2013). 
The issuance of first law for disabled people in Jordan dated back to 1989 under number (34). Then the disabled care law number (12) was issued in 1993. Correspondingly, the year 2007 witnessed the issuance of disabled people rights law number (31) for 2007, which involves these rights for disabled people: "providing the public transportation companies and tourism offices and car rent offices at least one transportation mean with specifications ensure for the disabled people its usage easily"(AlMajali \& Faddoul, 2008). However, since 2010, Jordan has witnessed many initiatives in the policy and legislations for the rights of disabled people:

$\checkmark$ The recognition of people with disabilities in Jordanian Constitution in 2011;

$\checkmark$ Legislative modifications to the election law securing the rights of voters with disabilities which were then employed in the parliamentary elections in 2012-2013;

$\checkmark$ University of Jordan has considered a policy to ensure equal access to higher education for students with disabilities in 2013;

$\checkmark$ Introduction of the Equal Opportunities Committee (EOC) to ensure employment rights in 2013 (CSP, 2013).

It is apparent that there has been much development in different aspects of accessible tourism in Jordan. In addition, the awareness has been raised toward the potential contribution of accessible tourism to the overall tourism industry in Jordan.

\section{Motivations of tourists with disabilities}

What motivates people taking part in different types of behaviour has occupied researchers and scholars long before it was explored in the tourism field (Page \& Connell, 2006). Nonetheless, a substantial amount of literature has been published on tourist motivation in recent decades and it is omnipresent in tourism studies (Singh, 2008). The task of tourist behaviour theories is to demonstrate the prosperous areas of tourist needs, as a source of data for researchers to employ in their specific investigations of "satisfaction, decision making and marketing" (Pearce \& Butler, 1994:116).

However, amotivation refers to a lack of motivation and it occurs when people do not realize the 'contingency' between their action and the reward or outcome of this action (Deci \& Ryan, 2004). Little attention has been paid to the amotivation state for different type of tourists. A possible explanation for this might be that it is a relatively difficult task to observe the behaviour and reactions of amotivated tourists. The amotivated tourists may also change their behaviour during the trip if they find a favourable outcome for their tourism activities (Allan, 2012). Accordingly, in their pilot study on accessible leisure tourism experiences in Portugal, Figueiredo et al. (2012) stated that there was a high interest and motivation for disabled people to engage in tourism and leisure activities, mostly if equipment and services are adapted to the particular needs stood by their different types of disabilities and levels of functioning. In his review of the motives for disabled tourists undertaking tourism experience in Jordan, Allan (2013) found that the initial motives for such tourists were 'Interest/Enjoyment' and their desired tourism activities were the historical and cultural attractions. A study by Buhalis and Michopoulou (2011) involved exploring the accessibility market and provides an estimate of its size in Europe. Moreover, it examined how ICTs can enable tourism destinations and organizations to capture the accessibility market and improve destination marketing. The findings of their study suggested that the accessible tourism market is heterogeneous and involves different subgroups with distinctive needs and requirements. The study also proved that the usage of the Information communication technologies (ICTs) can enable the tourist to address his/her needs and requirements. Elsewhere, Kim and Lehto (2012) investigated the leisure travel motivations and activities of Korean families with disabled children. Thus, they identified five motivational factors: "Children's intellectual skill's building", "Socializing", "Family competence (mastery)", "Relaxation and escape" and "Family closeness. However, their study identified five motivational factors and seven activity factors. Consequently, 'family competence (mastery)' was the most important motivational factor for families of disabled children. In an investigation into leisure travel motivations of active travellers with acquired mobility impairments, 
Shi et al. (2012) indicated that these travellers have their unique motivations. They further concluded that such travellers consider the travel as a way to regain independence and to be 'normal' again.

\section{Methodology}

Overall, the major aim of this study was to explore the intrinsic motivation, extrinsic motivation, amotivation state, and travel constrains for tourists with disabilities involving in different tourism experiences in Jordan. A quantitative approach has been applied in order to fulfil the aim of the study. An onsite intercept questionnaire was administered. It involved inviting a convenience sample of 226 Jordanian tourists with disabilities in 2013. The design of the questionnaire has based on existed scales and measures. Thus, the researcher used studies about SelfDetermination Theory (SDT) derived from the literature, in particular, the models of the questionnaires of those who developed the theory, Deci \& Ryan (2000) for the items of respondents' motivations. Moreover, items measuring travel constrains were extracted from previous studies (Smith, 1987; Lee et al., 2012). Data were collected from three travel agencies in Amman, two travel agencies in Irbid, the division of supporting students with special Needs at the University of Jordan, Yarmouk University, Ajlun University, the Panoramic Complex in the Dead Sea, and the visit centre in Wadi Rum. Only 226 questionnaires were retained for analysis after eliminating 74 incomplete questionnaires. The questionnaire was written in Arabic language adjusted by an Arabic language expert to ensure the validity and accuracy of the language of the questionnaire. All the respondents were asked to participate in the on-site questionnaire after the researcher had introduced the nature and objectives of the research. Based on their agreement, the respondents were given a copy of the questionnaire to complete based upon their personal capabilities; the respondents were left to complete the questionnaire at their leisure. However, Sign Language Interpreters accompanying the disabled tourists were helping the respondents to complete the questionnaire. A five point Likert-type scale was used to respond to the items. The scale ranged from 'not true' (1) to 'true" (5). The data collected from the convenience sample was entered into the software package SPSS (Statistical Package for the Social Sciences Version 17) and frequencies and cross tabulations were performed (Jennings, 2010).

\section{Results}

Among the 226 valid respondents, $71.7 \%$ of them are males, and $28.3 \%$ are females. Most of the respondents are young and middle aged $(54.4 \%)$. In term of educational level, the results indicate that the majority of the respondents are well educated (45.1\%). Moreover, most of the respondents have a low annual income $(86.1 \%)$ and they prefer to travel with tourists group $(76.1 \%)$. Their preferred mean of transport is the private car $(35.4 \%)$. In relation to the type of respondents' disability, a large portion of respondents have physical disabilities (Table 1).

Table 1. Sample characteristics $(\mathrm{N}=226)$

\begin{tabular}{|c|c|c|}
\hline Demographic Items & Value & Percent (\% \\
\hline \multirow[t]{2}{*}{ Gender } & Male & 71.7 \\
\hline & Female & 28.3 \\
\hline \multirow{4}{*}{$\begin{array}{l}\text { Age } \\
\text { (Years) }\end{array}$} & $18-34$ & 54.4 \\
\hline & $35-39$ & 18.6 \\
\hline & $40-49$ & 18.1 \\
\hline & $\begin{array}{l}50-59 \\
60+\end{array}$ & $\begin{array}{l}8.4 \\
0.4\end{array}$ \\
\hline \multirow[t]{4}{*}{ Educational level } & Primary & 9.3 \\
\hline & $\begin{array}{l}\text { Secondary/ high school } \\
\text { Diploma }\end{array}$ & $\begin{array}{l}16.8 \\
17.3\end{array}$ \\
\hline & Undergraduate & 45.1 \\
\hline & Post-graduate & 11.5 \\
\hline \multirow{5}{*}{$\begin{array}{l}\text { Income level } \\
\text { (JOD) }\end{array}$} & Below 3000 & 68.1 \\
\hline & $3001-6000$ & 23.9 \\
\hline & $6001-9000$ & 5.8 \\
\hline & $9001-10000$ & 0.9 \\
\hline & +10000 & 0.4 \\
\hline \multirow[t]{2}{*}{ Trip type } & Group & 76.1 \\
\hline & Individual & 23.9 \\
\hline \multirow{6}{*}{ Means of transport } & t Car & 35.4 \\
\hline & Taxi & 3.5 \\
\hline & Rental car & 7.1 \\
\hline & Bus & 20.8 \\
\hline & Train & 0.4 \\
\hline & Plane & 32.7 \\
\hline \multirow[t]{6}{*}{ Disability } & Physical & 82.3 \\
\hline & Hearing & 0.4 \\
\hline & Visual & 14.6 \\
\hline & Psychological & 0.4 \\
\hline & Multiple & 0.4 \\
\hline & Other & 1.8 \\
\hline
\end{tabular}




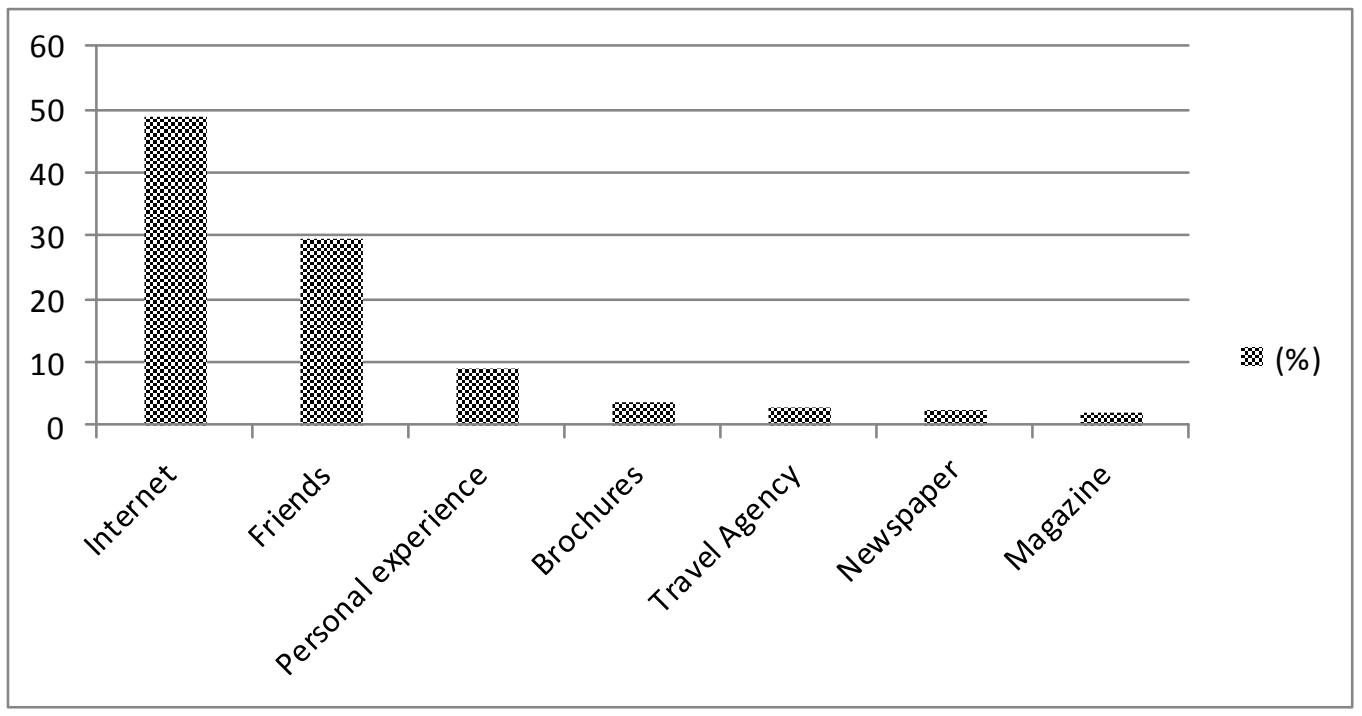

Figure 1. Sources of information for the respondents

Table 2. Intrinsic motivation of respondents

\begin{tabular}{lccc}
\hline Measures & Mean & SD & $\begin{array}{c}\text { Number of responses } \\
\text { (n= 226) }\end{array}$ \\
\hline Knowledge & $\mathbf{4 . 2 2}$ & $\mathbf{0 . 7 3 6}$ & $\mathbf{2 2 5}$ \\
To learn new things & 4.26 & 0.492 & 225 \\
To increase my knowledge & 4.19 & 0.981 & 226 \\
Relaxation & $\mathbf{4 . 2 6}$ & $\mathbf{0 . 8 3 8}$ & $\mathbf{2 2 6}$ \\
To relax and rest & 4.57 & 0.646 & 226 \\
To refresh my mental and physical state & 3.96 & 1.030 & 226 \\
Escape & $\mathbf{4 . 2 8}$ & $\mathbf{0 . 8 6 0}$ & $\mathbf{2 2 5}$ \\
To escape from the daily life routine & 4.51 & 0.701 & 225 \\
To escape from the pressure of work & 4.05 & 1.020 & 226 \\
Enjoyment & $\mathbf{4 . 2 4}$ & $\mathbf{0 . 8 2 8}$ & $\mathbf{2 2 6}$ \\
It is exciting & 4.20 & 0.872 & 226 \\
To have fun & 4.28 & 0.784 & 226 \\
Friendship & $\mathbf{4 . 1 8}$ & $\mathbf{1 . 9 9 0}$ & $\mathbf{2 2 6}$ \\
To meet people with similar interests and & 3.70 & 1.160 & 226 \\
hobbies & & & \\
To travel with friends and my family & 4.67 & 1.820 & 226 \\
Sense of Wonder & $\mathbf{3 . 8 8}$ & $\mathbf{1 . 1 1 0}$ & $\mathbf{2 2 5}$ \\
Because it is an exotic place & 3.61 & 1.220 & 226 \\
To explore new places & 4.15 & 1.010 & 224 \\
\hline
\end{tabular}

As shown in the above figure, most of the respondents prefer to use the internet to source their information about the destinations before visiting them $(49 \%)$, whilst only $(1.5 \%)$ of the respondents rely on the Television to obtain the required information before undertaking their trips.

Regarding the intrinsic motivation, its mean scores ranged from 3.61 to 4.67 , whilst the standard deviations ranged between .462 and 1.99. The Cronbach Alpha for the intrinsic motivation items was 0.74 . However, the results indicate that the highest intrinsic motivations were escape factor $(M=4.82, S D$ $=0.860)$, relaxation $(M=4.26, S D=0.839)$, enjoyment $(\mathrm{M}=4.24, \mathrm{SD}=0.828)$, and knowledge gain $(M=4.18, S D=1.99)$ (See Table 2). 
Concerning the individual items measuring the intrinsic motivation for the respondents, the item, 'To travel with friends and my family', which is related to friendship factor, was the most frequent, its intrinsic motivation mean score being $(M=4.67, S D=1.82)$. Whilst the item, 'Because it is an exotic place', which is related to sense of wonder, was the least frequent of the intrinsic motivation items $(\mathrm{M}=$ 3.61, SD=1.22).

In the context of the individual items measuring the extrinsic motivation for the respondents, the item, 'Because it has many social, cultural and recreational advantages for me', which is related to identified extrinsic motivation, was the most frequent, its mean score being ( $\mathrm{M}=$ $4.02, \mathrm{SD}=0.903$ ). Table 3 shows the item, 'To show others that I am a distinct person', which is related to external regulations, was the least frequent of the intrinsic motivation items $(\mathrm{M}=$ $3.48, \mathrm{SD}=1.41)$.

In term of extrinsic motivation, the mean scores for the respondents ranged from 3.48 to 4.02 ; whereas the standard deviations for the items measuring extrinsic motivation ranged from 0.903 to 1.41 . The Cronbach Alpha for these items ranged from 0.71 to 0.74 . The main extrinsic motivations for the respondents were the identified extrinsic motivation ( $M=3.91, S D$ $=0.946)$, and introjected extrinsic motivation ( $M$ $=3.87, \mathrm{SD}=1.01$ ).

The three items measuring the construct amotivation showed lower mean scores than the previous two forms of motivation. Thus, the average amotivation scores ranged from 2.74 to 2.88 (Table 4). The standard deviations of the items measuring amotivation ranged between 1.34 and 1.55. The amotivation subscale was lower than the desirable, 0.67 according to the Cronbach guidelines. However, since that the number of the amotivation subscale items was only three, the internal reliability rate was considered to be at an acceptable level. This conclusion is in accord with Kaplan and Saccuzzo (2008) who postulate that reliability of the scale increases as the number of items increases.

Table 3. Extrinsic motivation of respondents

\begin{tabular}{|c|c|c|c|}
\hline Measures & Mean & SD & $\begin{array}{l}\text { Number of } \\
\text { responses } \\
(n=226)\end{array}$ \\
\hline Identified & 3.91 & 0.946 & 226 \\
\hline Because it has many social, cultural and recreational advantages for me & 4.02 & 0.903 & 226 \\
\hline Because I believe it is personally important to me to travel to the site & 3.80 & 0.990 & 226 \\
\hline Introjected & 3.87 & 1.010 & 226 \\
\hline In my life I need this type of tourism activity to be happy & 3.94 & 1.030 & 226 \\
\hline I must be occupied with activities & 3.80 & 0.990 & 226 \\
\hline External regulation & 3.51 & 1.360 & 226 \\
\hline To show others that I am a distinct person & 3.48 & 1.410 & 226 \\
\hline Because my family and friends tell me to do this activity & 3.55 & 1.320 & 226 \\
\hline
\end{tabular}

Table 4. Amotivation measurement results

\begin{tabular}{|c|c|c|c|}
\hline Measures & Mean & SD & $\begin{array}{l}\text { Number of } \\
\text { responses } \\
(n=226)\end{array}$ \\
\hline Not by choice; I don't care about this type of tourism activity & 2.97 & 1.34 & 226 \\
\hline I don't really know; I don't think that this type of tourism suits me & 2.88 & 1.38 & 226 \\
\hline $\begin{array}{l}\text { Honestly, I don't know; I think that I wasted my time in this type of tourism } \\
\text { activity }\end{array}$ & 2.74 & 1.55 & 226 \\
\hline
\end{tabular}


Table 5 illustrates the results of the extent of travel constrains, that is: intrinsic, interactive and environmental constrains, for the research cohort. The mean score for the three sub dimensions ranged from 2.95 to 3.84 . The standard deviations for their items ranged between 0.968 and 1.52. The Cronbach Alpha for the items, which measured the travel constrains, was 0.78 .

Overall, the results indicate that the intrinsic constrains had the highest mean score of the travel constrains $(\mathrm{M}=3.87 \mathrm{SD}=2.38)$, whereas the interactive constrains had the lowest score $(M=3.32, S D=1.28)$. In term of the individual items measuring the travel constrains for the respondents, the results indicate that the item 'Travel imposes requirements that are beyond my capabilities' was, which is referred to the intrinsic constrains received the highest mean score of all the travel constrains items $(\mathrm{M}=4.17, \mathrm{SD}=0.968)$, whilst the item 'Fear of getting hurt' which related to the interactive constrains polled the lowest mean score $(\mathrm{M}=2.95, \mathrm{SD}=1.22)$.

\section{Discussion}

The results revealed that the primary source of information for respondents was the Internet, followed by friends and relatives. The findings of the current study are consistent with those of Ray and Ryder (2003) who found that internet searches and word of mouth are popular strategies individuals with disabilities utilize to plan their trips. Buhalis (2003) postulates that disabled people have gained an influential and independent information source throughout the advent of the internet, with which to plan and arrange their vacations. Furthermore, Darcy and Daruwalla (1999) indicate that the internet can empower people with disabilities to search for detailed, reliable and up-to-date information as printed sources are frequently not sufficiently accurate. Also, the internet provides dynamic opportunities to decrease and simplify the search process.

Additionally, the results of this study showed that the main intrinsic motivations for the respondents were escape factor, relaxation and enjoyment, respectively. These results agree with the findings of other studies, in which the escape, relaxation and enjoyment factors are common factors for different types of tourists (Crompton, 1979; Iso-Ahola, 1982; Baloglu \& Uysal, 1996; Jang \& Cai, 2002, Allan, 2012).

In the extrinsic motivation context, the results of this study indicate that the identification of intrinsic motivation was the highest extrinsic

Table 5. Travel constrains of respondents

\begin{tabular}{lccc}
\hline Measures & Mean & SD & $\begin{array}{c}\text { Number of } \\
\text { responses } \\
\text { (n = 226) }\end{array}$ \\
& & & \\
& & 3.78 & $\mathbf{2 . 3 8 0}$ \\
\hline Intrinsic constrains & 4.17 & 0.968 & 226 \\
Travel imposes requirements that are beyond my capabilities & 3.81 & 1.130 & 226 \\
Being in a situation where I need others help to do something & 3.42 & 1.200 & 225 \\
Fear of doing something by myself & 3.48 & 1.140 & 226 \\
Fear of causing others discomfort and inconvenience & 3.51 & 1.520 & 226 \\
Doctors' recommendation for maintaining my health & 3.32 & 1.280 & \\
Interactive constrains & 3.78 & 1.310 & 226 \\
Fear of being ignored by others & 3.33 & 1.490 & 226 \\
Lack of experience on making friends & 3.37 & 1.160 & 226 \\
Fear of being an object of others' interest & 2.95 & 1.220 & 226 \\
Fear of getting hurt & 3.19 & 1.290 & 225 \\
Fear of others' prejudice against me & 3.42 & 1.280 & \\
Environmental constraints & 3.63 & 1.400 & 226 \\
Inconvenient facilities & 3.69 & 1.250 & 226 \\
My condition require me to wear assistive devices & 3.04 & 1.330 & 226 \\
Inconvenient transportation facilities to use & 3.42 & 1.170 & 226 \\
Inappropriate physical conditions of tourist destinations & 3.35 & 1.250 & 224 \\
\hline Lack of my physical ability to move around freely & & &
\end{tabular}


motivation for the respondents. Following this, the identification of extrinsic motivation indicates that the reasons for doing any particular activity are incorporated within oneself. Thus, it is an internalized and selfdetermined action such that one performs an activity because it is judged to be valuable by him (Deci \& Ryan, 1991).

The tourists' responses show a high degree of agreement with the values and significance of their tourism experience, such that they agree that their tourism experience has many social, cultural and recreational advantages for them; they also deem that it is personally important to them to travel to their potential site.

In terms of amotivation state, the three items measuring the construct amotivation showed lower mean scores than the previous two forms of motivation. However, the findings of the current study do not support the previous research suggested that most respondents in different life contexts have low amotivation to engage in behaviour (Ntoumanis, 2001; Baker, 2004; Spittle et al., 2009; Allan, 2012).A possible explanation for these results may be the lack of accessibility for such tourists. According to Smith (1987), disabled tourists' satisfaction with tourism may be lesser than that of other types of tourists, because significant aspects of the general experience may be inaccessible to them. Accordingly, negative attitudes were the most limiting barriers encountered by people with disabilities and the most difficult to overcome (Smith et al., 2001).

It is evident that the respondents' motivation has stimulated by internal and personal needs more than by external motivations. It seems possible that these results are due to the fact that leisure activities are mostly motivated by intrinsic factors (Iso-Ahola, 1983). This also accords with Neulinger (1974) who postulated that most of the leisure studies indicated that leisure is intrinsically motivated and individuals experience it for its own sake, without expecting external rewards.

What is surprising is that the results of this study showed that travel intrinsic constrains represented the main influence on the respondents undertaking their tourism experience. It seems that the travel constrains for the respondents stem from the self rather than the external constrains. Kennedy, Smith and Austin (1991)argue that these constrains may be directly connected to an individual's exact disability, however they may also be caused by a lack of sufficient knowledge about tourism opportunities, ineffective social skills, physical and psychological dependency upon caregivers, and skill/challenge incongruousness. In accordance with the present results, previous studies have demonstrated that intrinsic constrains are considered as the major barriers for tourists with disabilities (McGuire, 1984; Smith, 1987; Murray \& Sproats, 1990).

\section{Conclusion}

Overall, this study was carried out to enhance the existing body of knowledge addressing issues related to development of accessible tourism in Jordan. The researcher found that the main intrinsic motivations for the study respondents were the escape, relaxation and enjoyment factors and the main extrinsic motivations for the respondents was the identified extrinsic motivation. The study respondents expressed a high level of amotivation. In terms of travel constrains for the respondents, it is found that travel intrinsic constrains had the highest influence on them. A key policy priority should therefore be to improve the accessibility of tourism supply in Jordan and provide free-barrier tourism products. Nevertheless, better understanding motivations and travel constrains for disabled tourists will help managers, promoters and policy-makers to improve their products and services for such tourists. The tourism management, policy-makers and practitioners should pay more attention to the disabled tourists segment in the tourism market and add their voices to the tourism discourse.

Some limitations to this study need to be acknowledged. The scope of the study locations was restricted to five sites in Jordan due to travel and cost constrains. Therefore, the current study did not include a large portion of tourism sites in Jordan. Also, the chosen sample was restricted to the tourists with disabilities who were aged 18 and above. 
Moreover, the current investigation was limited by applying a restricted number of common motivation items repeatedly used in the tourism literature. However, there is a wide range of motivational factors in the tourism literature and some of such motivations only were used in a specific tourism destination or a specific type of tourism. According to Jewell and Crotts (2001), the usage of predetermined motivation items is problematic because the researcher cannot guarantee that these items cover the most significant motives of the respondents.

Further research might explore the people with disabilities as tourism employees and the potential difficulties for them to work in tourism and hospitality industry in Jordan. Additionally, Future research could concentrate on the investigating of children with disabilities as tourists. Within the field of accessible tourism, few studies have investigated the issue of the amotivation state for tourists with special needs. Thus, considerably more work could be done to examine the nature and scope of amotivation for different kinds of tourists with special needs to better understand this phenomenon.

\section{Acknowledgment}

The author would like to express his deepest thanks and appreciation to the Deanship of Academic Research (DAR), the University of Jordan for their support, as this project was totally supported by a research grant funded by the University of Jordan.

\section{References}

Allan, M. (2013). Disability Tourism: Why do Disabled People Engaging in Tourism Activities? European Journal of Social Sciences, 39(3), 480-486.

Al-Majali, S., \& Faddoul, K. (2008). The Rights of Disabled people in the Hashemite Kingdom of Jordan As Per the National Legislative System and International Standards. Amman .

Avis, A., Card, J., \& Cole , S. (2005). Accessibility and attitudinal barriers encountered by travelers with physical disabilities. Tourism Review International, 8(3), 239-248.

Axelsson, C., \& Barrett, D. (2009). Access to Social Services for Persons with
Disabilities in the Middle East - Multistakeholder Reflections for Policy Reform Disability Monitor InitiativeMiddle East, CBM and Handicap International, Amman.

Baloglu, S., \& Uysal, M. (1996). Market Segment of Push and Pull Motivation a Canonical Correlation Approach. International journal of Contemporary Hospitality Management, 8(3), 32-38.

Baker, S. (2004). Intrinsic, Extrinsic, and Amotivational Orientations: Their Role in University Adjustment, Stress, WellBeing, and Subsequent Academic Performance. Current Psychology, 23(3), 189-202.

Burnett, J. J., \& Bender-Baker, H. (2001). Assessing the travel-related behaviors of the mobility-disabled consumer. Journal of Travel Research, 40(1), 411.

Bizjak, B., Knezevic, M., \& Cvetreznik, S. (2011). Attitude change towards guests with disabilities reflections from tourism Students. Annals of Tourism Research, 38(3), 842-857.

Buhalis, D. (2003). eTourism: Information Technology for Strategic Tourism Management. Harlow: Prentice Hall.

Buhalis, D., Michopoulou, E., Eichhorn, V.\& Miller, G. (2005). Accessibility market and stakeholder analysis - One-StopShop for Accessible Tourism in Europe (OSSATE). Surrey, United Kingdom: University of Surrey

Buhalis, D., \& Michopoulou, E. (2011). Information-enabled tourism destination marketing: addressing the accessibility market. Current Issues in Tourism, 14(2), 145-168.

Buhalis, D. \& Darcy, S., (2010). Accessible Tourism: Concepts and Issues: Channel View Publications.

Burns, N., Paterson , K.\& Watson , N. (2009). An inclusive outdoors? Disabled people's experiences of countryside leisure services. Leisure Studies, 28(4), 403-417.

Crompton, J. L. (1979). Motivations for Pleasure Vacation. Annals of Tourism Research, 6, 408-424. 
CSP. (2013 ). Jordan's Disability Movement: shifting from needs to rights. Amman: USAID.

Darcy, S. (1998). Anxiety to Access: The tourism patterns and experiences of New South Wales people with a physical disability. Tourism New South Wales, Sydney

Darcy, B., S. \& Daruwalla, P. (1999). The Trouble with Travel: People with Disabilities and Tourism. Social Alternatives, 18(1), 41-46.

Darcy, S.\& Dickson, T. (2009). A Whole-of-Life Approach To Tourism: The Case for Accessible Tourism Experiences. Journal of Hospitality and Tourism Management, 16, 32-44.

Deci, E. \& Ryan, R. (1991). A motivational approach to self: Integration in personality. In R. Dienstbier (Ed.), Nebraska Symposium on motivation. Perspectives on Motivation (Vol. 38, pp. 237-288). Lincoln, NE University of Nebraska Press.

Disabled World (TM). (2012). World Facts and Statistics on Disabilities and Disability Issues. URL : http://www.disabledworld.com/disability/statistics/\#ixzz2HJt 698Oj (Accessed on 01 May 2013)

Eichhorn, V., Miller, G., Michopoulou, E.\& Buhalis, D. (2008). Enabling access to tourism through information schemes. Annals of Tourism Research, 35(1), 189-210.

European Commission. (2014). Economic impact and travel patterns of accessible tourism in Europe - final report. European Commission - DG Enterprise and Industry.

Figueiredo, E., Eusébio, C.\& Kastenholz, E. (2012). How Diverse are Tourists with Disabilities? A Pilot Study on Accessible Leisure Tourism Experiences in Portugal. International Journal of Tourism Research, 14, 531550.

Foggin, S.E.A. (2000). The Experience of Leisure Tourism of People with Disabilities. Unpublished PhD thesis, Faculte des Erudes Superieures, Universite de Montreal, Montreal.

Harris Interactive Market Research. (2005). Research among adults with disabilities
- travel and hospitality. Chicago: Open Doors Organization

Higher Council for Affairs of Persons with Dsaibilities. (2014). Statistics. URL: http://hcd.gov.jo/ar/content/\%D8\%A8\% D9\%8A\%D8\%A7\%D9\%86\%D8\%A7\% D8\%AA-\%D8\%A5\%D8\%AD\%D8\% B5\%D8\%A7\%D8\%A6\%D9\%8A\%D8\% A9 (Accessed on $05^{\text {th }}$ of October 2014) Iso-Ahola, S. \& Allen, J. (1982). The Dynamics of Leisure Motivation: The Effects ofOutcome on Leisure Needs. Research Quarterly for Exercise and Sport, 53, 141-149.

Jang, S.\& Cai, L. (2002). Travel motivations and destination Choice: A Study of British Outbound Market. Journal of Travel and Tourism Marketing, 13(3), 111-133.

Jennings, G. (2010). Tourism Research (2 ed.). Milton, Qld.: Wiley John Wiley \& Sons, Milton.

Kaplan, R. \& Saccuzzo, D. (2008). Psychological Testing: Principles, Applications, andlssues (7 ed.). Belmont: Cengage Learning.

Kennedy, D. W., Smith, R. W.\& Austin, D. R. (1991). Special recreation: Opportunities for persons with disabilities (2nd ed.). Dubuque, IA: William C. Brown.

Kim, S., \& Lehto, X. (2012). Leisure Travel of Korean Families of Children with Disability: Motivation and Activities. Tourism Management, 37, 13-24.

Lee, B. Agarwal, S. \& Kim, H J. (2011). Influence of travel constraints on people with disabilities intention to travel: an application of Seligman's helplessness theory. Tourism Management, 33, 569-579.

McGuire, F. (1984). A factor analytic study of leisure constraints in advanced adulthood. Leisure Sciences, 6, 313326.

MIUSA. (2013). Spotlight on Jordan: Leadership in the Middle East on Disability Rights. URL: http://www.miusa.org/publications/book s/muslimworld/jordan (Accessed on 05 May 2013)

Murray, M. \& Sproats, J. (1990). The disabled traveller: Tourism and disability in 
Australia. Journal of Tourism Studies, $1(1), 9-14$

Neulinger, J. (1974). The psychology of leisure: Research approaches to the study of leisure. City University of New York (CUNY): Thomas (Springfield, III)

Neumann, P., \& Reuber, P. (2004). Economic Impulses of Accessible Tourism for All (Vol. 526). Berlin: Study commissioned by the Federal Ministry of Economics and Technology \& Federal Ministry of Economic and Labour (BMWA).

Ntoumanis, N. (2001). A self-determination approach to the understanding of motivation inphysical education. British Journal of Educational Psychology, 71(2), 225-242.

Page, S. \& Connell, J. (2006). Tourism: a modern synthesis. London: Cengage Learning EMEA.

Pearce, D., \& Butler, R. (1994). Tourism Research: Critiques and Challenges. London: Routledge.

Peters, S. (2010). Review of marginalisation of people with disabilities in Lebanon, Syria and Jordan . UNESCO.

Poria, Y., Reichel, A., \& Brandt, Y. (2010). The Flight Experiences of People with Disabilities: An Exploratory Study. Journal of Travel Research, 49(2), 216227.

Ozturk, Y., Yaylı, A. \& Yesiltas, M. (2008). Is the Turkish Tourism Industry Ready For Disabled Customers' Market? The Views of Hotel and Travel Agency Managers, Tourism Management, 29(2), 382-389.

Ray, N. \& M. Ryder (2003). "Ebilities" Tourism. An Exploratory Discussion of the Travel Needs and Motivations of the Mobility Disabled. Tourism Management, 24(1), 57-72.

Richards, V., Pritchard , A.\& Morgan , N. (2010). Envisioning tourism and visual impairment. Annals of Tourism Research, 37(4), 1097-1116.

Rutherford, K. (2007). Jordan and disability rights: A pioneering leader in the Arab world. The Review of Disability Studies: An International Journal, 3(4), 25-42.

Shi, L., Cole, S., \& Chancellor, H. (2012). Understanding Leisure Travel Motivations of Frequent Travelers with
Acquired Mobility Impairments. Tourism Management, 33(1), 228-231.

Singh. T. (2008). Fundamental of Tourism and Travel. Delhi: Gyan Publishing House.

Smith, R. (1987). Leisure of disable tourists: Barriers to participation. Annals of Tourism Research, 14 (3), 376-389.

Smith, R., Austin , D.\& Kennedy , D. (2001). Inclusive and Special Recreation: Opportunities for Persons with Disabilities (4th ed.). Madison, WI: Brown \& Benchmark.

Spittle, M., Jackson, K. \& Casey, M. (2009). Applying self-determination theory to understand the motivation for becoming a physical education teacher. Teaching and Teacher Education, 25, 190-197.

Turmusani, M. \& Sime, J. (1994). Evaluation Report on the Disability Provision in Jordan, Amman: GUVS.

Turmusani, M. (1999). The Economic Needs of Disabled People in Jordan: from the Personal to the Political Perspective, Disability Studies Quarterly, 19 (1), 4054.

USAID. (2013 ). Jordan Tourism Development Project II - Final Report 2008 - 2013. USAID.

Turmusani, M. (2003). Disabled people and economic needs in the developing world: A political perspective from Jordan. Ashgate: UK.

United Nations. (2003). Barrier-free tourism for people with disabilities in the Asian and Pacific region. New York: UN.

World Health Organization (WHO). (1980). International Classification of Impairments, Disabilities and Handicaps - a manual of classification relating to the consequences of disease. Geneva: World Health Organization

Woodside, A.G. \& Etzel, M.J. (1980). Impact of physical and mental handicaps on vacation travel behaviour. Journal of Travel Research, 18(3), 9-11.

Yau, K., McKercher, B.\& Packer TL. (2004). Traveling with a disability: more than an access issue. Annals of Tourism Research, 31(4), 946-960. 